\title{
Extraction of Indigo from Some Isatis species and Dyeing Standardization Using Low-technology Methods
}

\author{
Nazan Comlekcioglu ${ }^{1 *}$, Lale Efe ${ }^{2}$ and Sengul Karaman ${ }^{1}$ \\ ${ }^{1}$ Biology Department; Kahramanmaras Sutcu Imam University; Kahramanmaras - Turkey. ${ }^{2}$ Crop Fields \\ Deparment; Kahramanmaras Sutcu Imam University; Kahramanmaras - Turkey
}

\begin{abstract}
Fresh leaves of four Isatis species culture form of I. tinctoria L and wild forms of I. buschiana Schischkin, I. candolleana Boiss. (endemic) and I. tinctoria L. subsp. corymbosa. (Boiss.) were used for indigo production. Dyes were extracted by fermentation and hot water application. The extracted dyes were optimized with different $\mathrm{pH}$ and reducing agents. Results showed that the dye from hot water application produced the desired dying quality at $\mathrm{pH}$ 11. Reducing agent concentrations had no significant effect on color quality. Dark blue and blue colors were obtained from I. tinctoria and I. candolleana extracts although I. tinctoria subsp. corymbosa and I. buschiana produced mostly yellow-gray colors. Light, dry and wet rubbing fastness values varied between 3 and 3/4 while washing fastness was between 2 and 4/5. The highest indigo amounts were determined spectrophotometrically as $4.19 \mathrm{mg} / \mathrm{g}$ and $2.53 \mathrm{mg} / \mathrm{g}$ in I. tinctoria and I. candolleana, respectively. Results also showed that harvesting season was important for indigo production and the highest indigo amount was observed in mid-June.
\end{abstract}

Key words: Isatis spp., woad, indigo, natural dye, fermentation, fastness, spectrophotometry

\section{INTRODUCTION}

Most of the dyes used in textile industries are synthetic (Gilbert and Cook 2001) but there has been an increasing interest about natural dyes in fabric coloration. This is because of the stringent environmental standards imposed by many countries in a response to the toxic and allergic reactions associated with synthetic dyes (Kamel et al. 2005). Among the naturals dyes, indigo has been obtained from a variety of plant sources such as Indigofera tinctoria, Polygonum tinctorium, Nereum tinctorium and Isatis tinctoria (Gilbert and Cook 2001; Tozzi et al. 2005). However, once its chemical synthesis from aniline was established, it has been largely produced by chemical industry and almost superseded natural indigo (Bechtold et al. 2002; Puchalska et al.
2004). Natural indigo is produced by fermenting the leaves of indigo bearing plants. During the fermentation, indican in the leaves is hydrolized to form indoxyl and glucose by the action of endogenous $\beta$-glucosidase and subsequently oxidized to form indigo in contact with air (Song et al 2010). Although indigo could be produced from the plants in large quantities, the decrease in trade of the natural indigo has been mainly due to the lack of knowledge with regard to simple production of natural indigo from plant material and high production cost (Gilbert and Cook 2001; Bechtold et al. 2002). Beyond the technical approach of dyeing to achieve the displacement of synthetic with natural dyes, the requirement of modern dyehouse and dye manufacturers should be considered (Bechtold et al. 2003).

*Author for correspondence: noktem @ksu.edu.tr 
Isatis tinctoria L. (woad, Brassicaceae), which is an ancient European dye and medicinal plant, has a long and well-documented history (Brattström et al. 2010; Han et al. 2011). Successful cultivation of $I$. tinctoria in mountain and marginal areas offers an alternative to traditionally grown crops (Spataro et al. 2007); therefore, I. tinctoria could be an important indigo source for natural dyeing applications. There are several reports on the extraction of indigo from I. tinctoria leaves (Balfour-Paul 1998; Stoker et al. 1998; Gilbert et al. 2004; Tozzi et al. 2005; Sales et al. 2006; Angelini et al. 2007; Rocha et al. 2011). Simple extraction method is required for an effective and ecological production of natural indigo (Bechtold et al. 2002). Detailed information is needed for a basic optimized and standardised extraction of indigo precursors and dye formation. The dye yield is usually low with traditional fermentation method.

The aim of this study was to develop an efficient and eco-friendly method for coloring textiles by using natural indigo and to determine the amount of indigo potentials in the plants. Hence, four different species of Isatis genus were cultivated and rosette leaves of the plants used as raw materials for extraction. Natural dyestuff extractions and seasonal indigo production from culture and native species of Isatis were tested and dyeing potentials were compared.

\section{MATERIALS AND METHODS}

\section{Material}

Fresh leaves of four Isatis species (culture form of I. tinctoria and wild forms of I. buschiana, I. candolleana (endemic) and I. tinctoria subsp. corymbosa) were used for indigo production. The seeds of I. tinctoria were provided from IPKInstitute for Plant Genetics and Crop Plant Research, Gatersleben, Germany and were grown in Kahramanmaras/Turkey. I. candolleana, I. buschiana, and I. tinctoria subsp. corymbosa were biennial, while I. tinctoria was annual in trial field. The other wild species were collected from South-East Mediterranean Region of Turkey. All of the specimens were identified according to the Flora of Turkey (Davis 1965). Cotton yarn was used as cellulose material for the dyeing experiments. Raw cotton yarn was soaked in 500 $\mathrm{mL}$ tap water for $1 \mathrm{~h}$ before the dyeing treatments.

\section{Extraction of Indigo}

Rosette leaves were harvested from the cultivated plants by cutting $10 \mathrm{~cm}$ from the ground they reached about $30 \mathrm{~cm}$ in the end of May and early June. Leaves $(100 \mathrm{~g})$ were washed and cut into small pieces of $1 \mathrm{~cm}^{2}$. The dyestuff was then extracted by using $1000 \mathrm{~mL}$ of hot water $(60,70$ or $80^{\circ} \mathrm{C}$ ) or fermentation $(24 \mathrm{~h})$. Two different $\mathrm{pH}$ (9.0 and 11.0) and four different reducer $\left(\mathrm{Na}_{2} \mathrm{~S}_{2} \mathrm{O}_{4}\right.$, Sigma) concentrations $(1,5,10$ and 20 $\mathrm{g} \mathrm{l}^{-1}$ ) were tested in extraction experiments. All the experiments were repeated three times and mean values were used.

\section{Fermentation Application}

Plant materials $(100 \mathrm{~g})$ were fermented in 1000 $\mathrm{mL}$ water for $24 \mathrm{~h}$ in the dark and placed at the room temperature. The extraction liquor was divided into two equal volumes and the $\mathrm{pH}$ adjusted to 9.0 and 11.0 using $2 \mathrm{~N} \mathrm{NaOH}$ (Merck) solution. Extraction liquor was aerated for $1 \mathrm{~h}$ by using a compressor to enable complete oxidation of the indigo precursors (Stoker et al. 1998; Chanayath et al. 2002).

\section{Hot Water Application}

The extraction was carried out at temperatures of 60,70 or $80^{\circ} \mathrm{C}$ for $10 \mathrm{~min}$. The leaves were removed and the sample was rapidly cooled to $50^{\circ} \mathrm{C}$. Extraction medium was divided into two equal volumes and the $\mathrm{pH}$ adjusted to 9.0 and 11.0 with $2 \mathrm{~N} \mathrm{NaOH}$ solutions. The extract was aerated by using a magnetic stirrer until the blue color development (Stoker et al. 1998; Balfour-Paul 1998).

\section{Reduction Step}

The $\mathrm{pH}$ adjusted dye solutions were equally divided into $100 \mathrm{~mL}$ volumes and then $\mathrm{Na}_{2} \mathrm{~S}_{2} \mathrm{O}_{4}$ $\left(1,5,10\right.$ and $\left.20 \mathrm{~g} \mathrm{~L}^{-1}\right)$ was added for reduction of indigo. After that the cotton yarns $(1 \mathrm{~g}$ yarn/100 $\mathrm{mL}$ dye solution) were soaked in it and incubated for $60 \mathrm{~min}$ at $50^{\circ} \mathrm{C}$ in water bath. During the dyeing process, stirring and aeration were performed manually every $15 \mathrm{~min}$ for $1 \mathrm{~min}$. Finally, dyed cotton yarns were rinsed with tap water (approx. $500 \mathrm{~mL}$ ) three times for the removal of excess unbound dyes.

\section{Fastness Tests}

Color fastness tests on dyed samples were carried out using ISO standard methods. The light fastness of the yarns was examined by using the 
ISO/FDIS 105-B02. Then, color fading was evaluated by comparing each sample with standard blue scale. The washing fastness of the samples was also tested on the basis of

ISO 105-C06:2010. Dry and wet rubbing fastness of the samples were tested using ISO 105X12:2001and ISO 105-X16:2001 methods. Shade changes in washing and rubbing fastness were determined using a grey scale (Marks $1-5,1=$ poor, 5 = excellent).

\section{Indigo Extraction and Sample Preparation for Spectrophotometry}

Indigo content of leaves was extracted following Stoker et al. (1998) and Sales et al. (2006) with some modifications. The chopped leaves (approx. $1 \mathrm{~cm}^{2}$ in size) were weighed $(1.0 \mathrm{~g})$ and placed in tubes containing $10 \mathrm{~mL}$ of distilled water. Then the tubes were immersed in a boiling water bath for $10 \mathrm{~min}$ and cooled rapidly in ice bath. The leaf pieces were removed and $\mathrm{NaOH}$ solution was added to adjust the $\mathrm{pH}$ at 11.0. Samples were then aerated for $30 \mathrm{sec}$ and allowed to stand at room temperature $\left(20-25^{\circ} \mathrm{C}\right)$ for $1 \mathrm{~h}$ before acidification to $\mathrm{pH}$ 1.0-2.0 with $\mathrm{HCl}$ (Merck). After $30 \mathrm{~min}, 5.0$ $\mathrm{mL}$ of ethyl acetate (Merck) was added to $1.0 \mathrm{~mL}$ aliquot of sample and the absorbances were measured at $600 \mathrm{~nm}$. Finally, indigo concentrations were calculated by using the indigo calibration curve. Calibration curve was prepared by dissolving indigo standard (Sigma) in ethyl acetate (Sales et al. 2006). Experiments were repeated three times and mean values were used.

\section{RESULTS AND DISCUSSION}

The extraction of dye components from the plant materials was performed with hot water and fermentation without the addition of chemicals or solvents. The results on the effects of $\mathrm{pH}$, fermentation and temperature levels on dyeing potentials of Isatis species by using $1 \mathrm{~g} \mathrm{l}^{-1}$ reducing agent are shown in Table 1 . The main colors obtained from I. tinctoria, I. candolleana and I. tinctoria subsp. corymbosa were dark blue, blue and gray-blue, respectively (Table 1).

Table 1 - Effects of temperature and $\mathrm{pH}$ on dyeing performances of Isatis species.

\begin{tabular}{|c|c|c|c|c|c|c|}
\hline & \multicolumn{2}{|c|}{ I. tinctoria } & \multicolumn{2}{|c|}{ I. candolleana } & \multicolumn{2}{|c|}{ I. tinctoria subsp. corymbosa } \\
\hline & pH 9 & pH 11 & pH 9 & pH 11 & pH 9 & pH 11 \\
\hline $60^{\circ} \mathrm{C}$ & & & & & & \\
\hline $70^{\circ} \mathrm{C}$ & & & & & & \\
\hline $80^{\circ} \mathrm{C}$ & & & & & & \\
\hline Fermentation & & & & & & \\
\hline
\end{tabular}

No blue color was obtained from I. buschiana, therefore this plant was not studied in further experiments. The desired blue colors were obtained from $I$. tinctoria in all hot water extraction treatments at $\mathrm{pH} 11.0$; however, extraction with fermentation failed to give blue color. The success in hot water extraction could possibly be due to leaf epidermal wax melting.
Blue colors were also observed in I. candolleana extraction at $\mathrm{pH} 11.0$ using both hot water and fermentation. The extraction carried out at the 70 and $80^{\circ} \mathrm{C}$ give similar blue colors with I. tinctoria and I. candolleana; therefore, the extractions at $70^{\circ} \mathrm{C}$ could be favorable for energy saving. Blue colors obtained from I. tinctoria subsp. corymbosa were lighter than that of $I$. tinctoria. This 
difference between these closely related species could be due to their genetical makeup. The production of indigo precursors are affected by genetical differences (Angelini et al. 2007), hence, indigo producing capacity varies among the plants (Spataro et al. 2007). High dyestuff containing plants and easy extraction with water are the desired factors for the selection of dye plant (Bechtold et al. 2003).
The effects of reducer concentrations in dyeing were studied at $70^{\circ} \mathrm{C}$ and $\mathrm{pH}$ 11.0. Difference in color obtained by different reducer concentrations was insignificant (Table 2). Color improvement was not also observed with increasing concentration of reducer in I. tinctoria subsp. corymbosa.

Table 2 - Effects of reducer concentrations on dyeing performances of Isatis species.

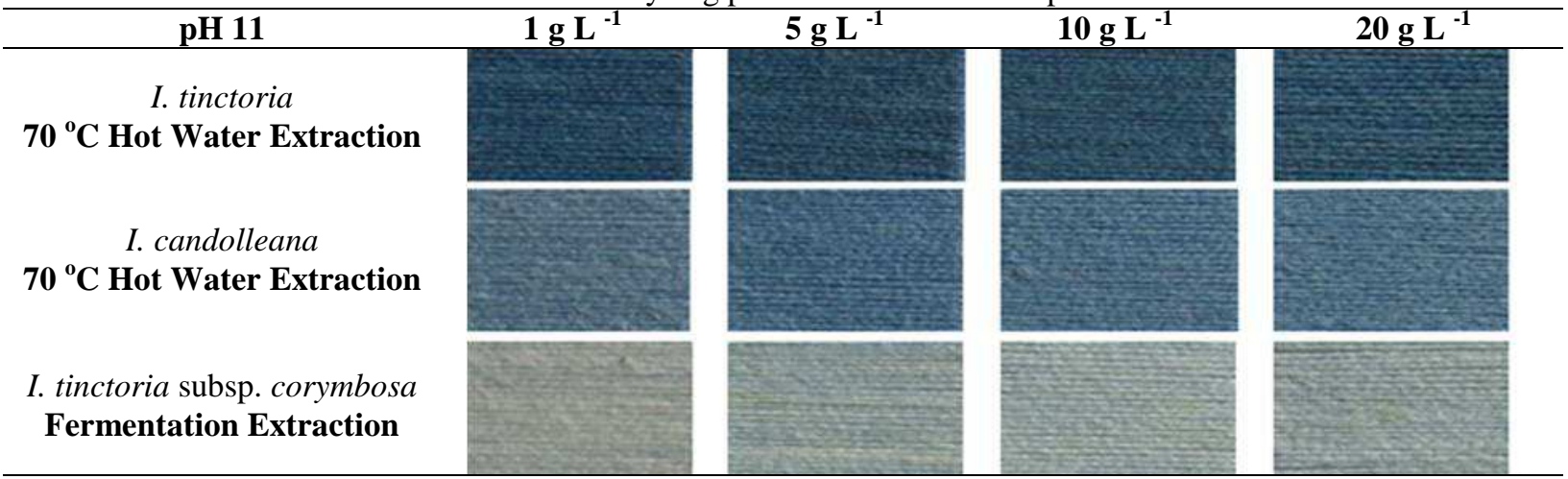

Various shades of blue color were obtained in all the tested Isatis species, except I. buschiana. The shades of light blue were much more than yellowgreenish and were obtained in I. tinctoria subsp. corymbosa while the most desired blue colors were obtained from I. tinctoria and I. candolleana. In caustic-hydrosulphite method, which is widely used to reduce indigo, dyeing vat is generally prepared in $80 \mathrm{~g} \mathrm{l}^{-1}$ concentration. An excess of reducing agent results in irregular dyeing and increase of ecological damage (Kumbasar et al. 2006). For this reason, the control of $\mathrm{pH}$ and reducing agent concentrations are very important and this study represents an environmental friendly process with a small amount of hydrosulphite resulting succesfull dyeings. Hot water extraction method was reported as the most suitable choice to fulfill the extraction immediately after the harvest (Bechtold et al. 2002). It was simple and the yield could be obtained in the same day; however, this method required higher energy consumption. Energy consumption is not necessary for extraction with fermentation, but bad odor and overflows are the main problems and extra time is required for better results. However, simple and rapid dyeing process, no intermediate drying steps and one bath dying are the requirements of a technical dyehouse
(Bechtold et al. 2003). Both the techniques studied here met these requirements.

\section{Fastness Properties}

The requirements for natural colorants in textile industry are the quality of fastness properties as well as color appearance in terms of reproducibility (Kumbasar et al. 2006). Washing fastness of the samples ranged in 2 to $4 / 5$ for $I$. tinctoria; $2 / 3$ to $4 / 5$ for I. candolleana; 3 to $4 / 5$ for I. tinctoria subsp. corymbosa (Table 3 ). Poor or insufficient washing fastness could be identified as a limitation for the use of natural dyes extracted from the different representative sources. Sufficient dyestuff fixation also can be seen as a good mark for washing fastness bleeding (Bechtold et al. 2006). The dry rubbing fastness ranged in $3 / 4$ to 4 for $I$. tinctoria and $I$. candolleana; 4/5 for I. tinctoria subsp. corymbosa. The wet rubbing fastness ranged in 3 to $3 / 4$ for $I$. tinctoria and I. candolleana, 3/4 for I. tinctoria subsp. corymbosa. The light fastness grade 2 or 3 was required as the lowest limit for positive selection; however, values of light fastness could be increased by further investigations to exceed the limit of grade 2-3 (Bechtold et al. 2006). Our results showed that light fastness grade were 3 and 3/4 for I. tinctoria and 3 for I. candolleana while $2 / 3$ for I. tinctoria subsp. corymbosa. All the 
results presented were at an acceptable light fastness level. The light fastness is also influenced by various factors such as chemical and physical properties of dye, dye concentration, nature of fibers (Cristea and Vilarem 2006; Guinot et al. 2006). Padfield and Landi (1996) also stated that indigo was much more light resistant on wool than that of cotton. In this study, the impurities in dyebath, which was released from raw cotton yarn, could reduce the affinity of dye particules to cotton yarn, therefore low fastness results could be caused by these impurities.

In the market, the main features of indigo-dyed denim fabrics demand has to meet the low washing fastness, average light fastness and low dry-rubbing resistance (Kumbasar et al. 2006). In this study, acceptable values for light, rubbing and washing fastness were obtained for denim fabrics (Table 3).

Table 3 - Fastness properties of dyed cotton yarn.

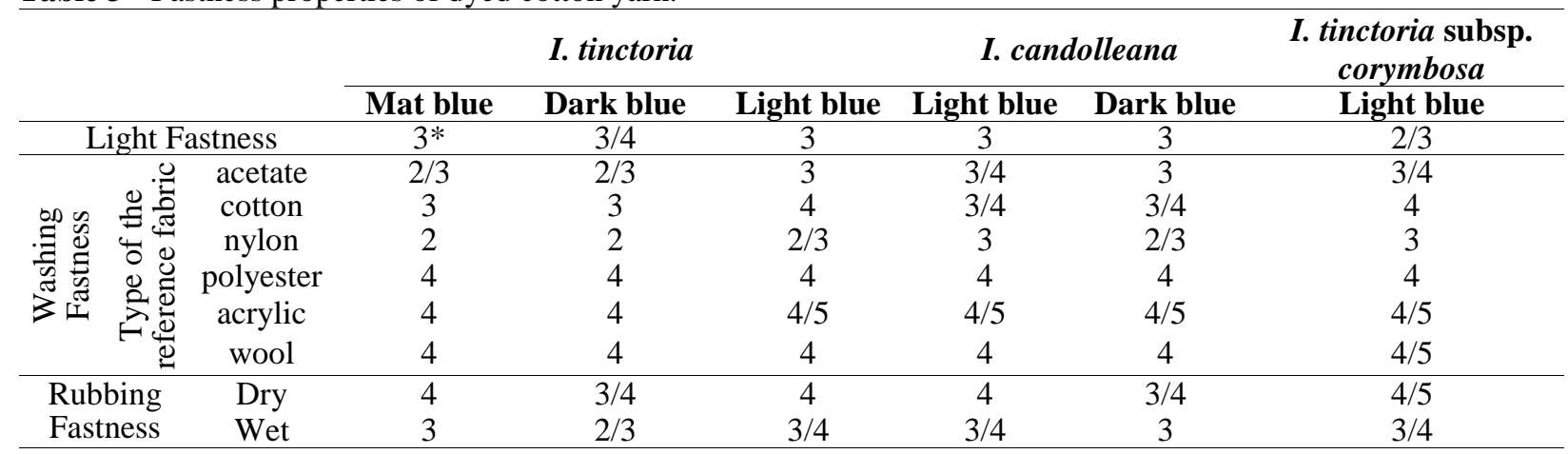

*Scores for fastness tests: 1- Poor, 2-Weak, 3- Average, 4-Good, 5-Excellent

\section{The Amount of Indigo}

Seasonal variations of indigo were determined in Turkish native Isatis species and compared with $I$. tinctoria. Significant differences in indigo production were found between the species in growing season. The seasonal change in the amount of indigo production was determined and indigo extraction was performed between April 1 and August 7 from plant leaves with two-week interval. Seasonal course of indigo is shown in Figure 1. Indigo content generally increased from beginning of April until the mid of June, and began to decrease with temperature increase until beginning of July, then remained stable until the middle of August. Rosette plants completed their vegetative development in August. The highest indigo value was recorded at mid June in $I$. tinctoria.

The results of indigo content in Isatis spp. are given in Table 4. Indigo content were higher in $I$. tinctoria and I candolleana than I. tinctoria subsp. corymbosa while indigo could not be detected in $I$. buschiana. Mean indigo content measured in fresh leaves of $I$. tinctoria and $I$. candolleana ranged from 0.34 to $4.19 \mathrm{mg} \mathrm{g}^{-1}$ and 0.01 to $2.53 \mathrm{mg} \mathrm{g}^{-1}$, respectively. I. tinctoria subsp. corymbosa produced indigo in a range from 0.3 to
$0.78 \mathrm{mg} \mathrm{g}^{-1}$, which was $80 \%$ lower than that of $I$. tinctoria. These results were also supported with the dyeing experiments (Table 1). Blue colors obtained from I. candolleana were close to the colors from I. tinctoria. I. tinctoria subsp. corymbosa produced lighter blue colors; however, no blue colors were obtained from I. buschiana. The analysis showed that indigo reached to its maximum level in mid June, therefore mid-June could be the best time to harvest.

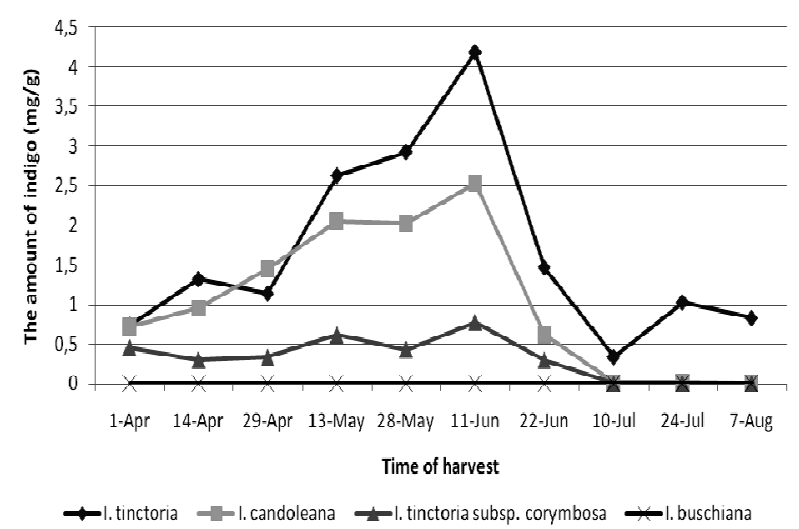

Figure 1 - Seasonal variation of indigo content in Isatis spp. leaves. 
Table 4 - Seasonal variation of indigo content in Isatis spp $\left(\mathrm{mg} \mathrm{g}^{-1}\right)$. The values represent the mean \pm standard deviation.

\begin{tabular}{|c|c|c|c|c|}
\hline \multirow[b]{2}{*}{ Harvest Dates of Leaves } & \multicolumn{4}{|c|}{ Isatis species } \\
\hline & I. tinctoria & I. candolleana & I. tinctoria subsp. corymbosa & I. buschiana \\
\hline $\mathbf{1}^{\text {st }} \mathrm{Apr}$ & $0.74 \pm 0.07$ & $0.72 \pm 0.09$ & $0.46 \pm 0.05$ & ND \\
\hline $14^{\text {th }} \mathrm{Apr}$ & $1.32 \pm 0.07$ & $0.95 \pm 0.11$ & $0.30 \pm 0.04$ & ND \\
\hline $29^{\text {th }} \mathrm{Apr}$ & $1.14 \pm 0.12$ & $1.45 \pm 0.11$ & $0.34 \pm 0.02$ & ND \\
\hline $13^{\text {th }}$ May & $2.63 \pm 0.26$ & $2.05 \pm 0.12$ & $0.62 \pm 0.13$ & ND \\
\hline $28^{\text {th }}$ May & $2.93 \pm 0.24$ & $2.02 \pm 0.28$ & $0.43 \pm 0.10$ & ND \\
\hline $11^{\text {th }} \mathrm{Jun}$ & $4.19 \pm 0.06$ & $2.53 \pm 0.23$ & $0.78 \pm 0.03$ & ND \\
\hline $22^{\text {nd }}$ Jun & $1.47 \pm 0.16$ & $0.62 \pm 0.07$ & $0.30 \pm 0.05$ & ND \\
\hline $10^{\text {th }} \mathrm{Jul}$ & $0.34 \pm 0.04$ & $0.01 \pm 0.02$ & ND & ND \\
\hline $24^{\text {th }} \mathrm{Jul}$ & $1.03 \pm 0.16$ & $0.02 \pm 0.06$ & ND & ND \\
\hline $7^{\text {th }}$ Aug & $0.83 \pm 0.31$ & ND & ND & ND \\
\hline
\end{tabular}

ND: Not detected

This study presented an indigo content between 0.34 to $4.19 \mathrm{mg} \mathrm{g}^{-1}$, which was confirmed by Gilbert et al. (2004) and Angelini et al. (2007)'s previous observations. Angelini et al. (2007) reported that the harvest time had significant effect on leaf yield and indigo amount. They also stated that the genetical factor was another important criterion that affected the production of indigo precursors. Therefore, in this study, different Isatis species produced different indigo yield as a result of their genetic makeup. High temperature, light intensity and inadequate rainfall could limit the plant growth and indigo amount (Stoker et al. 1998; Sales et al. 2006). Therefore, the decrease in indigo in late-June could be due to the climatic changes.

\section{CONCLUSIONS}

Following cultivation of the plant material, a simple procedure for the extraction of indigo precursors was investigated in terms of crop and dye quality, aiming to bring some contribution to the knowledge of Turkish native Isatis species as a new potential dyeing plant. The study focused on the determination of indigo production potentials and effect of harvest times for indigo contents in Isatis spp. Results confirmed that indigo yield and quantity depended on the genetic factors, harvest time and extraction conditions. Extracted dye from I. candolleana was comparable to I. tinctoria. Thus, I. candolleana could be a promising plant for indigo dyeing. However, I. tinctoria subsp. corymbosa and I. buschiana were not suitable for this purpose.

\section{ACKNOWLEDGEMENT}

We thank Kahramanmaras Sutcu Imam University for funding of this study (Grant no: 2009/1-1D). Valuable helps of Dr. Ashabil AYGAN are also gratefully acknowledged.

\section{REFERENCES}

Angelini LG, Tozzi S, Nassi N. Differences in leaf yield and indigo precursors production in woad (Isatis tinctoria L.) and Chinese woad (Isatis indigotica Fort) genotypes. Field Crop Res. 2007; 101: 285-295.

Balfour-Paul J. Indigo. London: British Museum Pres, 1998.

Bechtold T, Turcanu A, Geissler S, Ganglberger E. Process balance and product quality in the production of natural indigo from Polygonum tinctorium Ait. Applying low technology methods, Bioresource Technol. 2002; 81: 171-177.

Bechtold T, Turcanu A, Ganglberger E, Geissler S. Natural dyes in modern textile dyehouses-how to combine experiences of two centuries to meet the demands of the future? J Clean Prod. 2003; 11: 499509.

Bechtold T, Mussak R, Mahmud-Ali A, Ganglberger E, Geissler S. Extraction of natural dyes for textile dyeing from coloured plant wastes released from the food and beverage industry. J Sci Food Agr. 2006; 86: 233-242.

Brattström A, Schapowal A, Kamal MA, Maillet I, Ryffel B, Moser R. The plant extract Isatis tinctoria L. extract (ITE) inhibits allergen-induced airway inflammation and hyperreactivity in mice. Phytomedicine, 2010; 17(8): 551-556. 
Chanayath N, Lhieochaiphant S, Phutrakul S. Pigment Extraction Techniques from the Leaves of Indigofera tinctoria Linn. and Baphicacanthus cusia Brem. and Chemical Structure Analysis of Their Major Components. CMU J. 2002; 1: 149-160.

Cristea D, Vilarem G. Improving light fastness of natural dyes on cotton yarn. Dyes Pigments. 2006; 70: 238-245.

Davis PH. Flora of Turkey and The East Aegean Islands, edited by PH Davis, Edinburgh at the University Press, Volume I. 1965, 287-307.

Gilbert GK, Cooke DT. Dyes from plants: Past usage, present understanding and potential. Plant Growth Regulation. 2001; 4: 57-69.

Gilbert KG, Maule HG, Rudolph B, Lewis M, Vandenburg H, Sales E, et al. Quantitative analysis of indigo and indigo precursors in leaves of lsatis spp. and Polygonum tinctorium. Biotech Prog. 2004; 20: 1289-1292.

Guinot P, Roge A, Gargadennec A, Garcia M, Dupont D, Lecoeur E, et al. Dyeing plants screening: an approach to combine past heritage and present development. Color Technol. 2006; 122: 93-101.

Han J, Jiang X, Zhang L. Optimisation of extraction conditions for polysaccharides from the roots of Isatis tinctoria L. by response surface methodology and their in vitro free radicals scavenging activities and effects on IL-4 and IFN- $\gamma$ mRNA expression in chicken lymphocytes. Carbohydrate Polymers. 2011; 86(3): 1320-1326.

ISO 105-C06:2010 Textiles - Tests for colour fastness. Part C06: Colour fastness to domestic and commercial laundering

ISO/DIS 105-X12 Textiles - Tests for colour fastness. Part X12: Colour fastness to rubbing.

ISO/DIS 105-X16 Textiles - Tests for colour fastness. Part X16: Colour fastness to rubbing, small areas.

ISO/FDIS 105-B02 Textiles - Tests for colour fastness. Part B02: Colour fastness to artificial light: Xenon arc fading lamp test.

Kamel MM, El-Shishtawy RM, Yussef BM, Mashaly H. Ultrasonic assisted dyeing III. Dyeing of wool with lac as a natural dye. Dyes and Pigments. 2005; 65: 103-110.

Kumbasar EPA, Aydın H, Ondogan Z, Ozcelik M, Ondogan EN. Automatic indigo measurement system as part of a dosing system for indigo dyeing. Fibres Text East Eur. 2006; 14: 86-90.
Padfield T, Landi S. The light-fastness of the natural dyes. Stud Conserv. 1996; 4: 181-196.

Puchalska M, Polec-Pawlak K, Zadrozpna I, Hryszko $\mathrm{H}$, Jarosz M. Identification of indigoid dyes in natural organic pigments used in historical art objects by high-performance liquid chromatography coupled to electrospray ionization mass spectrometry. J Mass Spectrom. 2004; 39:1441-1449.

Rocha L, Carvalho C, Martins S, Braga F, Carnide V. Morpho-agronomic characterization and variation of indigo precursors in woad (Isatis tinctoria L.) accessions. Plant Genetic Resources. 2011; 9(02): 206-209.

Sales E, Kanhonou R, Baixauli C, Giner A, Cooke D, Gilbert K, Arrilaga I, Segura J, Ros R. Sowing date, transplanting, plant density and nitrogen fertilization affect indigo production from Isatis species in a Mediterranean region of Spain. Indust Crop Prod. 2006; 23: 29-39.

Song J, Imanaka H, Imamura K, Kajitani K, Nakanishi $\mathrm{K}$. Development of a highly efficient indigo dyeing method using indican with an immobilized $\beta$ glucosidase from Aspergillus niger. J Biosci Bioeng. 2010; 110: 281-287.

Spataro G, Paola T, Valeria N. Genetic Variation and Population Structure in a Eurasian Collection of Isatis tinctoria L. Genetic Resources Crop Evol. 2007; 54 (3): 573-584.

Stoker KG, Cooke DT, Hill DJ. An improved method for the large-scale processing of woad (Isatis tinctoria) for possible commercial production of woad indigo. J Agr Eng Res. 1998; 71: 315-320.

Tozzi S, Lercari B, Angelini LG. Light Quality Influences Indigo Precursors Production and Seed Germination in I. tinctoria L. and I. indigotica Fort. Photochem Photobiol. 2005; 81: 914-919.

Received: December 13, 2013; Accepted: September 30, 2014. 